\title{
Who Would Propel Post-Communist Universities - The Challenge Of Motivation
}

Gabriella Keczer, University of Szeged, Hungary

\begin{abstract}
Motivation is an outstanding priority of human resource management. A person is motivated to make efforts and perform by the desire to satisfy his needs. So when we deal with the issue of motivation at the workplace, the first thing we have to learn is what needs employees may have, and we also have to check which of these needs the workplaceljob concerned is likely to meet and which are those that will have been left partially or totally unsatisfied. In my theoretical paper building on the need theories of Maslow, McClelland, Vroom, Porter-Lawler and Adams I analyze which basic needs the post-communist universities (state-owned higher educational institutions of the former communist countries) are likely to meet and those needs that will be partially or completely left unsatisfied. I conclude that post-communist universities are unable to meet the needs of those people who are, in each organization, the cornerstones of the future, development, competitiveness: they are the talented youth, the creative innovators and the committed leaders.
\end{abstract}

Keywords: human resources management, need theories, motivation, university management

\section{INTRODUCTION}

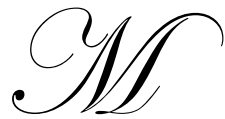

otivation is an outstanding priority of human resource management. Its primal aim is to set up and run such a politics of motivation that will promote the achievement of the organization by hiring proper staff, and, then, providing sufficient motivation for the member of the staff and maintaining working force. Its further aim is to incite employees to go through working hours without fail, develop competence and skills, focus on promotion and contribute to the achievements of their units of organization as much as possible (Gulyás 2006).

In post-socialist countries the system of public servants exercises a constraint -- besides on hiring the best working force possible, and the firing of those who work less satisfactorily - on motivating employees. Payment is constrained and so is the legal status. In addition, output is not measured. Promotion and evaluation etiquettes, the way leaders are selected, the nature of management and the organization culture at universities decrease the motivation of some of the members of faculty.

\section{NEEDS AND MOTIVATION}

A person is motivated to make efforts and perform by the desire to satisfy his needs. So when we deal with the issue of motivation at the workplace, the first thing we have to learn is what needs employees may have, and we also have to check which of these needs the workplace/job concerned is likely to meet and which are those that will have been left partially or totally unsatisfied. If a workplace can permanently meet the basic needs of its employees, workers stay strongly motivated for long. If, however, basic needs are left unsatisfied, employees are becoming increasingly less motivated. Besides, needs that have not been met for a long time will sooner or later lead to frustration. If this has become the case the employee's primary concern is going to be the dissolution of the situation that has initiated frustration followed by a possible resignation in case of those who, with sufficient competence and diligence, would get another job easily. This way a working place will lose the best of its human resources. Those, on the other hand, who are not able to get another job and have to stay, or who, for some reason or other, decide to stay will be trying to satisfy their needs in other areas of life, while, at their jobs, they will be working at an average 
level or, even, at a minimum level, surviving with a bitter resentment.

Now we shall have a look at those basic needs which the post-socialist universities are likely to meet and at those needs that will be partially or completely left unsatisfied.

\section{Maslow's Pyramid of Needs and Alderfer's Theory}

Maslow (1943) distinguishes five levels of human needs. These are the following: physiological needs, safety, love/ belonging, esteem and self-actualization.

- $\quad$ Physiological needs, for Maslow, include such basic material needs as food, drink, homeostasis and, on the other hand, such instinctual needs as sexuality or parenting. I think, nowadays, physiological needs - with the exception of the most defenseless strata of society - imply quality food, drink and homeostasis. Sexual and parenting instincts are extended to good living circumstances, the securing of the prosperity of one's offspring. (Another outstanding theorist of needs is Herzberg who, in his two-component theory, denies that motivation could be attached to the lower levels - which is, for him, the level of hygienic needs - of the pyramid of needs. Maslow, in fact, designed his theory with reference to the average citizen of the United States in the forties, while Herzberg built on the welfare society of the 1960s.) Whether we stick to the original interpretation or we level this category, this layer of the hierarchy is the one that is implied by material conditions and income.

- $\quad$ The second level of the pyramid hosts security, the maintenance of the standard of living, the constancy, accountability, reliability, orderliness, security and predictability of everyday activities and, in addition to these: the corresponding physical and emotional setup.

- The need for love refers to the demand for loving and understanding partners, belonging to a community, and for positive social bonding.

- $\quad$ The need for esteem, appreciation is essentially a demand for self-confidence and a positive view of ourselves verified by others; and that we ought to have a sufficient level of professional prestige, social status, power and attention focused on us. Our surroundings should acknowledge and appreciate our performance and achievements.

- $\quad$ Finally, self-actualization is the need for becoming who we have been thinking ourselves capable of becoming - to be able to set out novel, interesting and challenging aims for ourselves, and conditions ought to be arranged so that we could achieve these and we may develop without fail.

Henceforth we are examining how far the post-socialist university is ready to meet these needs.

- $\quad$ The level of wages - with the exception of professors and higher posts in management - is low. The majority are not able to secure a living that would match traditional middle class standards for themselves and for their families. Consequently they can satisfy their basic physiological needs only at a lower standard. Waging irrespective of performance does not allow them to earn, with more effort and with an increased working load, some extra payment over their basic salary. Earlier occupying a second job at other universities provided a chance to earn extra income. But this was not a choice for the freshmen in the profession. Nowadays these chances are limited, on the one hand, by the stricter rules, and, on the other hand, by the waning volume of higher education. In some fields of science there are possibilities to get a complementing job in the competitive sector. But this does not motivate academic activities at the universities, on the contrary: it flies in the face of it. This is also the case when university employees take jobs abroad.

- Higher education, being somewhat untouchable, recently has been able to make those who have been working in it feel secure because the sector has had stability and a reliable hiring and firing routine. Few employments have been more secure and dependable than those working in public service, especially in higher education. But these days economic constraints and the decrease in the number of prospective students has been reducing this security. What is more: because of the lack of performance assessment and the system of termini and tenures even those who perform the best cannot be sure whether in case of a cutback they would not lose their jobs. Especially those young scientists who are hired with contracts are much less safe than those lecturers who have tenure and, perhaps, just because of this, perform worse. 
- $\quad$ The need for love can be satisfied by university communities that have a fine organizational culture and climate (c.f. the clan culture mapped by Cameron and Quinn, which is characterized by cohesion, collegiality and identification with the organization) on a high level. Promotion is regulated and the selection of unit leaders is more or less depending on seniority and, consequently, existential and positional struggle is considerably less fierce than in "competing" businesses. Members of the community have similar possibilities and payment, and decision-making are in the hands of democratically operating boards consisting of colleagues. Individual freedom is broad since at universities teaching (and in some fields this is also true for research) is independent of colleagues (and mostly also of management) so conflicts at university units are rare. Continuous and close co-operation with clients, that is, with students may also cope with the need for relatedness provided proper organizational culture exists. If, however, organizational culture is more aggressive (typical in market, hierarchic and adhocratic cultures of Cameron and Quinn) crops up either in teachers' or students' communities, and/or if, due to flaws in the management or to flaws in the system immoral competition, selfishness, strife and the satisfaction of individual demands win over collegiality, cohesion and identification, the university will be unable to satisfy the need for social bonding.

- University lecturers have a considerably high prestige in comparison with other occupational sets in spite of the fact that this is not reflected in their income. The lecturer's and the researcher's profession has not lost prestige for the majority of the society (yet), so it is ready to invoke esteem satisfactorily. Degrees and titles can be achieved in line with one's career in science. Ceremonies accompanying them formally signify recognition which is sealed, then, by rites of incorporation performed by the scientific communities. In case of good organizational culture and promotional routine based on effective performance this may significantly meet the need for esteem and recognition within a closer institutional and professional environment.

- $\quad$ As far as self-actualization is concerned teaching at universities and research projects could theoretically allow larger space for creativity, innovation and unique ideas and solutions. Post-socialist universities, however, are loaded with inertia, and have a system that has been rooted in strong self-righteous, sometimes even feudal, rigid traditions, are focusing on the past, are authoritan and will hardly open up for rapid and thoroughgoing changes. This specific routine of operation and organizational culture strongly limit the choices of the individual - and the satisfaction of the needs for self-actualization of those who have unusual personalities, attitudes and way of thinking.

This phenomenon can be generally explained by the inclination of academia to ossify. As brilliantly described by Lohmann (2004), individual scholars, disciplines and university departments all tend to ossify.

- Individual scholars ossify mainly because of their socialization. It takes about seven years for an uncommitted amateur to become an engaged scholar, and graduate school brainwashes the student to make him a "Fachidiot" equipped to make fine distinctions on one dimension while being blind to the existence of other dimensions. Plus, graduate school draws him into a scholarly community. It is the peer group that will write referee reports when he submits articles to journals and outside letters when he comes up for tenure. A scholar who changes horses in midcareer loses the support of his peer group and is forced to reinvent himself from scratch. It needs personal courage and willingness to take a risk, and these are not traits the tenure system selects for. That's why it is rare that somebody bucks the trend and cook up wild and wonderful ideas in midcareer.

- Disciplines ossify because of one of their most important function: to protect the established lines of inquiry. Disciplines are controlled by leading scholars, who decide collectively what to be published in top journals, who to be awarded tenure and which activity to be supported by grants and showered with honors. They have selection biases that support gerontocracy and the clones of themselves.

- $\quad$ Like disciplines, university departments consist of scholars who clone themselves in hiring and promotions because they feel emotionally more comfortable with people who think like them and feel threatened by newcomers with new ideas, because the new is the wicked. There are always some faculty in voting positions, who gets very anxious about hiring and promoting scholars who are better then they are, and for this alone mediocrity can beat excellence.

Alderfer's ERG theory (Existence, Relatedness and Growth) is very similar to that of Maslow's five-layer pyramid of needs. Alderfer appropriates the five-layer pyramid of needs into three broader categories: existence, 
relatedness and growth.

The nature and direction of self-actualization considerably depends on the type of character. We shall look into this issue using McClelland's model.

\section{McClelland's Paradigm}

McClelland distinguishes three needs that may explain motivation within a setting of the organization. (Bakacsi 2004)

- $\quad$ People with whom affiliation need dominates feel their self-actualization realized in acceptability and lovability. They are looking, in their office bonding, for cooperation and they try to avoid conflicts.

- $\quad$ For those who are driven by achievement need the inner drive is geared by success, the achievement and the exceeding of goals targeted for themselves. They are fond of jobs in which they can take personal responsibility in solving problems and in which they receive regular feedback.

- $\quad$ Persons driven by the need for power are keen on influencing others, controlling their environments and aspiring for leading positions at their workplaces.

McClelland's model provides similar conclusions to that of Maslow's theory: university is likely to meet affiliation needs generally, achievement needs partially and power needs only at a very limited extent.

- $\quad$ The partial satisfaction of needs for achievement is secured because in case sufficient effort and proper skills and competence are provided the fulfillment of personal goals and shaping new ones can be guaranteed and success depends mostly on the individual, not on the others. At post-socialist universities, however, some circumstances hinder the meeting of the need for growth: e.g. the lack of regular performance assessment and feedback; the obstacles against rapid individual progress (e.g. habilitation can only follow the achievement of a $\mathrm{PhD}$ degree after five years), defenselessness in front of the monitoring of the scientific community in research activities and, in teaching, defenselessness in front of students who are increasingly less prepared and less motivated. It is a further problem that university lecturers' performance is measured with reference to their scientific impact factor (number of publications and citation index): those teachers who want to do something valuable primarily in teaching cannot feel that they have achieved something worth recognition.

- $\quad$ Post-socialist universities are, however, the weakest at meeting the will to power. Universities have such decision-making etiquettes, distribution of the scope of authority and, what is more, have such culture of functioning that there is very little space left for strong leadership, for self-sufficient decisions made by unit heads, for operational freedom and, consequently, for outstanding managerial feats. The hierarchic structure of institutions makes it unlikely that someone from the bottom of the hierarchy barely with his outstanding performance, abilities, ideas to lead would attain considerable influence within a considerably short time. And if someone is aspiring for power because as a leader he or she would create, shape the organization according to his persuasions and drive it onto new paths, at post-socialist universities he will get disappointed. Leaders are voted for by the lead, and turkeys would never vote for Christmas. The majority of university employees vote for preserving the status quo and not for a change. The ghost of democratic decision-making, the traditions, the decentralized structure, the bureaucratic regulations, the appointed - not elected - co-leaders, and the pressure of getting measured for re-election in every 3-5 years all bind leaders' hands.

\section{Vroom's and Porter-Lawler's Theory of Expectancy and Adam's Equity Theory}

According to Vroom and Porter-Lawler's expectancy theory people expect that on account of the efforts they have made they can perform well, and as a result of this, they receive recognition. If the impact of performance or the rewards do not compare to the efforts made the employee's motivation wanes and he, accordingly, decreases his efforts. (Bakacsi 2004)

Effort $\rightarrow$ Impact $\rightarrow$ Reward 
The acquisition of impact in proportion to the effort spent at post-socialist universities may be hampered mainly in teaching -- by the following factors.

- $\quad$ Teaching essentially consists of the interaction between teachers and students. At present the liberal Higher Education Act in Hungary declares that the attendance of university lectures are optional so it may happen that a full time student would never ever visit any lecture. Competition for students and financing per capita force quite many lecturers, especially at second rank universities, not to fail students, not to set up strict requirements and not to burden them with serious working load. As a consequence of this lecturers will not be able to achieve good results in teaching even if they try very hard.

- $\quad$ Reward at post-socialist universities is not proportionate with effort and output because still there is no regular and objective performance assessment, and extra output is not recognized by extra payment. After achieving - primarily scientific - criteria professional promotion is secured and so is the complementary step up the ladder. But the national pay framework is standardized and there is no differentiation between the rewards of the persons within the same category. And since qualification reflects research performance, motivation based on rewards proportionate to production is missing especially in teaching. Reward, naturally, might not necessarily be limited to money. But at post-socialist universities no other forms of remuneration are regular, either.

If the theory of expectancy is complemented by Adam's equity theory (according to which we primarily expect that remuneration should be equitable relative to others' performance (Bakacsi 2004)) we can easily see that at post-socialist universities the equity need of those employees who perform better than the rest will remain basically unsatisfied. They would hardly find their financial recognition equitable in comparison with that of someone else being in the same salary category but working much less, or in comparison with the payment of someone with the same skills working in a more prosperous branch of economy. Post-socialist university is unfit to meet the demand that if someone works more he should also get paid more. This makes the majority of the employees (those who are not inspired by a passion for their profession sufficiently or those who, because of their average abilities or for some other reasons, do not have any chance to get promoted to a top managing position or to professorship) keep their performance at the average, and never go above it.

\section{SUMMARY}

Motivation in post-socialist university faculty, according to the theories of need, is lagging behind in terms of the following aspects.

- The motivation of low rank employees who, because of their low income, cannot provide for the physiological needs of their families sufficiently has not been tackled and, consequently, other appealing aspects of their work(ing place) cannot motivate them enough. Moreover, waging is inappropriate to acknowledge and remunerate individual accomplishment and does not inspire to greater efforts. Working with termed contracts these people, nowadays, in these circumstances, cannot take their jobs for granted and, consequently, their need for security is not satisfied. The rigid promotional policy at post-social universities is not appealing for the young, enthusiastic and talented ones who are aiming at a rapid career, security and success in proportion with their talents and efforts, readily undertaking extra work to get this done. This kind of young people can anchor the capability of an organization to develop, to operate efficiently and will provide inner reinforcement for its management.

- $\quad$ The needs of people who have been born to lead are not readily satisfied. Because of the lack of intracompetition, the rule of seniority and hierarchic operation, young people have less chances to become leaders even is they are talented and have proper leadership skills and ideas. The average ages of Hungarian university leaders are the following: rectors - above 59 years, vice rectors - near 57, deans - between 5657, vice deans - above 53 years (Forgó 2008). But it is not solely becoming the head of the unit that is constrained: the freedom to manage is also limited. Collective democratic decision-making, organizational culture strongly rooted in tradition and limited financial and economic-managerial choices strongly hinder heads of units to implement thoroughgoing changes and actuate something grand. The limited nature of possibilities frighten off those particular persons who would consider these challenges the most seriously. 
- It has not been tackled either how to motivate personalities who tread new paths, look for unique solutions while challenging the majority and questioning the omnipotence of unwritten law - to motivate especially those who realize themselves in teaching, not in research and who do not harvest publications and fatten citation indices. They, instead of the "scientific" socializing and self-management required for this would like to teach their pupils, develop curricula, and nurture talent. The specific culture of hierarchic operation and its conservative professional community do not appreciate aspirations that are different from the orthodox way of thinking and their "reward" is usually conflict, ostracism instead of recognition. Scientific impact is the provision for promotion even in teaching positions (habilitation requires a set number of publications and citations) and the efforts made while teaching in class are neither appreciated by the institutions nor by the students: it is not the way to satisfy teachers' need for self-actualization and for esteem. Post-socialist university does not appreciate creative committed teaching professionals in spite of the fact that the development of science has always been geared by revolutionary minds, and the basic activity of a university's operation is teaching.

We can sum up that post-socialist universities are unable to meet the needs of those people who are, in each organization, the cornerstones of the future, development, competitiveness: they are the talented youth, the creative innovators and the committed leaders. The organization is either unable to bind these people to itself at all or they may, after a while, leave the system (this is counter-selection) or even if they stay, because of increasingly decreasing motivation, they will be performing less and less effectively.

\section{CONCLUSIONS, SUGGESTIONS}

- $\quad$ Freshmen and employees working in lower academic positions with low payment and with termed contracts may be kept and motivated at the institution via an at least partial implementation of waging based on performance, and, in addition, with the prospect of a more rapid promotion. For this the general implementation of regular, impartial performance evaluation - monitoring teaching, research and other activities (communal and project activities, institutional chores) - is inevitable. This type of performance assessment has been applied at some universities, faculties for the satisfaction of most of the teaching staff. Decisions can only be made objectively concerning appointments, promotions and rewards if they are based on the evaluation of performance.

- $\quad$ The set waging map for public service employees provides a possibility for differentiation since it marks only the minimum wages for each category. But payment guaranteed in a contract is unlikely to reflect performance continuously. There should be a waging policy that is ready to reflect, in addition to a basic salary, the outstanding performance for a period or permanently. The payment of university employees in the United Kingdom is marked by the very same type of a central national pay framework we ourselves have in Hungary. There are universities, however, - for example the University of Leeds - where they have set up a reward policy of their own. They implemented a reward policy in 2003 to recognize outstanding performance. These can be awarded by each unit using the fund that has been provided for them by the university specifically for this. (For reasons of even chances professors cannot be awarded extra payment from this fund. For them there is a separate program running.) The program consists of the following components:

A one-off payment acknowledging the outstanding performance given during the previous 12 months. The performance ought to be in line with the objectives of the department and, on the other hand, it has to exceed the boundaries of the performance that could be expected in the position concerned.

- $\quad$ Regular remuneration for teachers in the lowest wages category so as to provide them with an acceptable level of income if they perform satisfactorily or better.

A one-off or regular remuneration for those who work in such key positions where scarce special skills and competence are required.

Promoting conference participation, financing external training projects, promoting sabbatical leave on account of a significant development in one's performance during the previous 12 months. (Keczer 2006)

- $\quad$ The intervals of stepping up the academic ladder might be reconsidered in one's scientific progress. To become an associate professor at a university with tenure one has to have habilitation and to do this it takes 
at least 10 years - in fact it takes minimum 12. In competing businesses to become a top manager takes a much shorter time. Those young strongly motivated professionals who perform outstandingly might become frustrated at the fact that some elder colleagues of theirs without scientific degrees may have been promoted within the prior system to become associate professors and now with a decreasing performance they get a much higher salary, they have tenure for ever while younger professionals have to stay stand-by for years even if they have satisfied each requirement - except aging - for a long time.

- The motivation of personalities who would make good leaders may be secured via the reform of the selection of leaders and the restructuring of university management. When selecting leaders managerial skills and competence ought to signify and, according to this, selecting a leader should not take the form of voting by the underlings: the leader ought to be appointed to his or her position. This would guarantee the independence of the leaders and would make it possible to make someone a leader with a rational reform program challenging the beloved status quo. Inner management systems should not be changed because of issues of motivation, but because they have not been effective and, consequently, they have been clogging the operation of institutions. But the implementation of proper changes would solve the issues of motivation as well. The most important objective of this reform would be to redefine scopes of authority: the singular responsible leader should be given much more freedom and authority to decide and manage without the consent of boards that have been voted for in a democratic election. (If with the revision of the system of selecting leaders the best nominees would get the power, the greater scope would not imply a greater risk.) This way leaders would have sufficient independence and freedom to get their ideas realized instead of becoming marionettes who maintain the status quo so that their community would extend their contracts.

- $\quad$ To appreciate the performance of devoted teachers there should be a system that is similar to the balanced scorecard used by companies: it evaluates the particular aspects of performance in a balance. It is a fact that scientific performance can be qualitatively monitored easier via publications and citation indexes, but teachers' performance can also be reflected upon via the mapping of teaching hours, curricula development, talent tutoring (supervising theses, national scientific students' conference, PhD's) complemented by students' evaluations of teachers' performance. Proper teaching will naturally not do without research but I am convinced that to judge a university lecturer exclusively or primarily relying on their scientific performance is an age old paradigm. We are now very far from the Humboltian concept according to which lecturers at universities should be lecturing about their current investigations. A lecturer has to teach 5-10 different types of courses while his research has to focus - at least till the completion of the $\mathrm{PhD}$ and habilitation - on a single segment of a field since only publications referring to the particular field can be considered when awarding a degree. (And it is even worse when a lecturer teaches only a small segment of the field instead of giving an overview of that students might need in their studies.) Moreover in current mass-education universities are full of students who are so badly in want of preparation and who are so poorly capacitated intellectually that it is impossible to give them lectures of a scientific standard since for them even basic items of the episteme is difficult to get familiar with. Expected research activities should be converted so that people who primarily focus on teaching could fulfill academic requirements via the acquisition of recent theories and their application in the fields of their courses in order to disseminate upto-date knowledge, and primarily via curricula development and not via scientific publications.

\section{REFERENCES}

1. Bakacsi, Bokor, Császár, Gelei, Kováts, Takács: Stratégiai emberi erőforrás menedzsment, KJK, Budapest, 2004.

2. $\quad$ Forgó: Felsőoktatási vezetők karrierútja (Felsőoktatási Mühely, 2008/IV.)

3. Gulyás: A humán erőforrás menedzsment alapjai, JATEPress, Szeged, 2006.

4. Karoliny, Farkas, Poór, László: Emberi erőforrás menedzsment kézikönyv, Budapest, KJK, 2003.

5. Keczer: Humánerőforrás-menedzsment a Leeds-i Egyetemen - egy követhető példa (Humánpolitikai Szemle 2006/2.)

6. Lohmann: A Darvinian Medicine of Universities In: Ehrenberg, R. G.: Governing Academia. Cornell University Press, 2004.

7. Maslow: A Theory of Human Motivation, Psychological Review, 1943, Vol. 50 \#4, pp. 370-396. 


\section{NOTES}

